\title{
Nebule Dosing Unit
}

National Cancer Institute

\section{Source}

National Cancer Institute. Nebule Dosing Unit. NCI Thesaurus. Code C71204.

A dosing unit equal to the amount of active ingredient(s) contained in a nebule. 